\title{
SIGNIFICANCE OF RADIOGRAPHER AWARENESS IN PNEUMOTHORAX DETECTION
}

\author{
Saima Khan ${ }^{\text {l\&2 }}$, Sadaf Ahmed ${ }^{\text {l\&3 } \& \text { Shamoon Noushad }}{ }^{\text {\&4 }}$ \\ 1. Advance Educational Institute \& Research Center \\ 2. Aga khan University Hospital \\ 3. University Of Karachi, Department Of Physiology \\ 4. Institute of Basic Medical Sciences(DUHS)
}

Corresponding author: Saima.aeirc@gmail.com

\begin{abstract}
The purpose of the study is to aware and educated a radiographer of certain pathological conditions seen on chest $\mathrm{x}$ ray specifically we are dealing with types and severity of pneumothorax and the quality of information a radiographer communicate to his primary team for evaluation. Radiographer can identify or detect pneumothorax by taking x-rays in three positions i-e upright, supine or decubitis with complete awareness of diverse conditions of pneumothorax. For suitable imaging radiographer should know about position, safety of the patient and the techniques of Breath holding during exposure. Whereas ALARA (as low as reasonably achievable) should be kept standard. In our study mostly cases were of tension pneumothorax in which immediate decompression of thorax is mandatory and it requires instant action as on $\mathrm{x}$-ray film as lung marking diminishes in this condition. According to radiological policy for panic conditions the chest $\mathrm{x}$ - rays were observed through PACS after every two hours. We evaluated the role of radiographer in observing pneumothorax and how it is his/her utmost responsibility to inform their primary team or the concerned radiologist urgently. We observed 36 panic pneumothorax out of 2865 portable chest x-rays of admitted patients from May 2012 till November 2012. Out of these 36 cases radiographers correctly identified 28 cases while 6 were missed when compared with radiologists detection. We concluded that $77 \%$ of radiographers are aware of panic conditions detected on chest $\mathrm{x}$-ray but we find it very necessary to aware and educate radiographers more particularly to detect pneumothorax and related pathologies on chest x-rays in order to improve proper patient care in health care system and maintain required standards
\end{abstract}

\section{KEYWORDS}

pneumothorax, , decompression, tension pneumothorax, catamenial pneumothorax, endometriosis, Emphysema, pulmonary embolism, aspiration, congenital, perforations, atelectasis, asphyxia, tachypnea, transient tachypnea

\section{INTRODUCTION}

Radiographer can identify or detect pneumothorax by taking x-rays in three positions i-e upright, supine or decubitis and in these upright position is considered most preferable and accurate for detection, with complete awareness of diverse conditions of pneumothorax.In decubitis position concerned site should be kept upward and opposite side should touch the image receptor/cassette, x-ray source should be parallel to film. One factor that should be considered is to set the distance between image receptor and $\mathrm{x}$-ray source because as we increased the distance, magnification increases accordingly. The standard distance suggested by most radiographers is 72 inches for upright and 40-42 inches for decubitis.For suitable imaging radiographer should know about position, safety of the patient and the techniques of Breath holding during exposure. Whereas ALARA (as low as reasonably achievable) should be kept standard.In our study mostly cases were of tension pneumothorax in which immediate decompression of thorax is mandatory and it requires instant action as on x-ray film as lung marking diminishes in this condition.

Pneumothorax is a condition in which there is a free air in between the ribs, in between heart and the lungs that results in collapsing of lung of corresponding side. Incomparation of male to female pneumothorax differs depending on causes i.e catamenial pneumothorax is specified for females subjects (Nakamura H, 1986), a condition which occurs due to endometriosis. Males are more susceptible as they have the greater history of tobacco use (Sousa, 2011)where as tall, thin adolescent men are at higher risk (J Zhejiang 2010) . The ratio of male to female varies for primary and secondary pneumothorax i.e 6.2 :1for primary and 3.2 :1 for secondary pneumothorax (Melton, 1979).Emphysema,tuberculosis, lung cancer, endometrioses (Rousset-Jablonski, 2011), pulmonary embolism (Mathieson, 2012), pneumonia, ribs fracture, blunt trauma (Sharma, 2008)gunshot wounds, insertion of chest tubes are the causes of occurrence of pneumothorax.Factors like less weight, patients having underlying lungs pathologies may have recurrent pneumothorax. Recurrent pneumothorax risk increases with increased smoking and reduces in patients who undergoeschemical pleurodesis (Guo, 2005). The non-surgical treatment include aspiration and chest tube drainage in which chest tube is connected to one way valve or water seal system (J Zhejiang 2010). As compare to adults, paediatric chest wall has greater extensibility and resilence due to comparatively less rib mineralization. When compressed, paediatric ribs bends inside rather than breaking, as a result pernicious energy is discipated to underlying thoracic contents provided that peads may develop intrathoracic injuries even when there is no rib fracture.The main responsibility of radiographer is to have strengthened relationship with patient by improved communication for better outcomes. Radiographer believes that effectualness and powerfulness are more important than communication and they usually feel pressured. Its important to realized that in our current health care system patient's education is patient's right and providing this education is the foremost responsibility of radiographer.

\section{METHODOLOGY}

Accordingto radiological policy for panic conditions the chest x-rays were observed through PACS after every two hours We evaluated the role of radiographer in observing pneumothorax and how it is his/her utmost responsibility to inform their primary team or the concerned radiologist urgently.Data was collected from radiology information system, radiographers were supposed to identified the critical findings then the result obtained were compared with the findings of 
radiologists. We wanted to aware and educated a radiographer of certain pathological conditions seen on chest $\mathrm{x}$-ray specifically we are dealing withtypes and severity of pneumothorax and the quality of information a radiographer communicate to his primary team for evaluation.

\section{RESULTS}

We observed 36 panic pneumothorax out of 2865 portable chest xrays of admitted patients from May 2012 till November 2012. Out of these 36 cases radiographers correctly identified 28 cases while 6 were missed when compared with radiologists detection.

\section{CAUSES OF PNEUMOTHORAX}

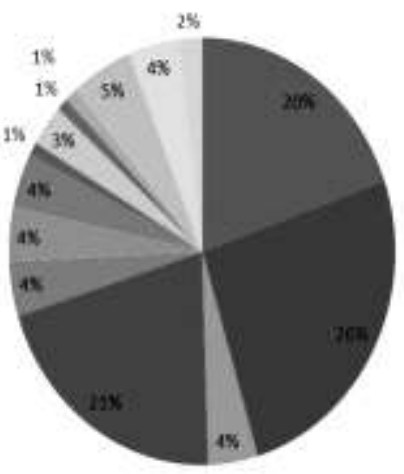

\author{
- EMTrisema \\ - atelectass \\ - COSTKC FIBROSIS \\ - pleupal gFassion \\ - Fracture \\ - TuBentoulosis \\ - AESPRATCCY OISTACSS \\ - Birth asranixia \\ -PPEIUMONIA \\ - trangont tachenpea \\ a PUIMONABR EMDOUSA \\ DPLUMCNARY HERNA \\ PIUMONARY EOEMA
}

\section{DISCUSSION}

The first investigation performed to assess pneumothorax is chest radiography as it is inexpensive, rapid and non-invasive but it is less sensitive than CT. different pathological conditions leads to pneumothorax but its severity depends on how deeply it persists. As a radiographer one should be aware of not only about detection and positioning for pneumothorax but also about the ethical issues related to patient care. The radiographer must first explain the whole procedure to patient to make the patient feel relaxed. It is also the responsibility of radiographer to use ALARA rule before setting the exposure which says the exposure should be as low as possiblein order to minimize the harmful effects as high radiation can cause burns and damage of internal organs. Pneumothorax can be detected by ultrasonography, CT-scan etc but first step we prefer is to go for upright chest X-ray. Before exposure patient should know the technique of deep breath and then stop breathing without breathing out atleast for a second. This has to be done because after taking deep breath lungs and chest cavity fully expands and taking image at that time clearly shows the pathologies as lung marking diminishes in pneumothorax condition. There are different causes of pneumothorax like in men having habit of smoking are at high risk of developing the conditions and smoking cessation appears to reduces risk of recurrency of pnemothorax(Sadikot, 1997). Researches shows that men are four times more susceptible as compare to female but such researches are applicable for Asian countries like Pakistan and India. For countries like America the ratio of male to female in relation to smoking habit is approximately same for male and females so the probability of developing pneumothorax is comparatively same. Another type of pneumothorax common in females is catamenial pneumothorax which is a result of endometriosis and female faces it just before onset or during menstrual cycle(Blanco, 1998). There is another theory that suggests air enters the peritoneum through the genital tract during menstruation then passes through congenital perforations in right hemidiaphragm resulting in pneumothorax(Lillington, 1972).Symptoms include severe pain in pelvic region that radiates towards chest region. Traumatic conditions like history of fall or accident or any gunshot injury that causes ribs fracture may results in traumatic pneumothorax (Getz Jr 1983; Sahn 2000). It can also be caused in post-operative patients in which there is insertion of chest tube if chest tubes misplaces from its site it will causes the air to leakout.(Alifano 2011). Other causes of pneumothorax includes emphysema, atelectasis, pulmonary oedema, pulmonary embolism, asphyxia, any alveolar damage, tuberculosis etc.Most common symptoms are tachypnea, slow and reduced chest expanded even with the deep breath, chest pain etc. The above study shows that radiographers awareness is fair i.e $77 \%$ are aware of pneumothorax critiques so it is a chief and essential requirement to originate awareness programs for radiographers about the pathophysiological conditions related to the injury incident, physiological status of patients and anatomical injuries. Moreover female population is relatively less susceptible than male population, although for certain pathological conditions male-to-female ratio is same. In accordance with the above study the main cause in males is "atelectasis" which is due to any bronchial obstruction with absorption of intra-alveolar gases, pleural filling or other changes in surfactant functions while this ratio is same for certain pathological conditions i.e "tuberculosis" (Primrose, W. R. (1984). It is also seen that amongest neonates pathology causing pneumothorax is "transient tachypnea" likely due to retained lung fluid and in this study it is the second most cause of pneumothorax.

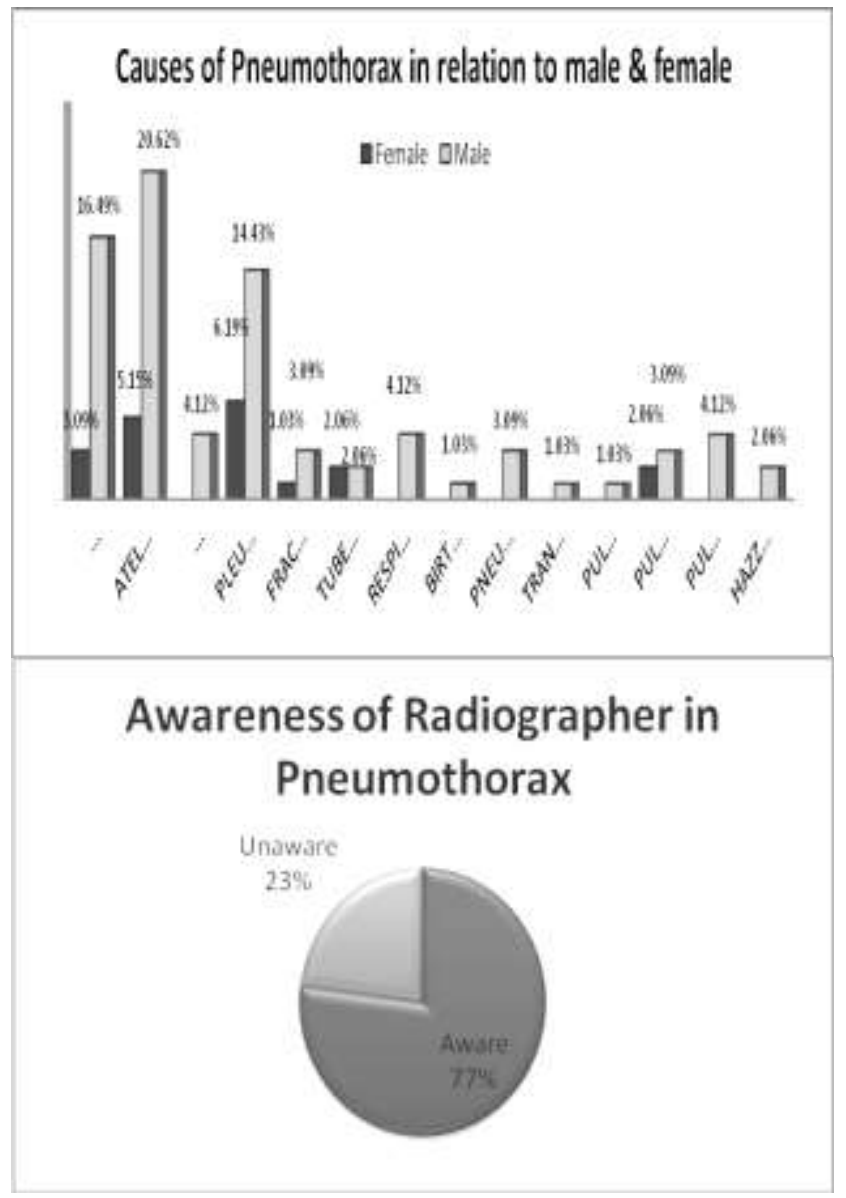

\section{CONCLUSION}

We concluded that $77 \%$ of radiographers are aware of panic conditions detected on chest $\mathrm{x}$-ray but we find it very necessary to 
aware and educate radiographers more particularly to detect pneumothorax and related pathologies on chest $\mathrm{x}$-rays in order to improve proper patient care in health care system and maintain required standards. The developmental and applications of new diagnostic tools have helped in influencing the management to better understand the pathogenesis of types and severity of pneumothorax especially the high resolution CT scan, but still there are many controversies in selection of optimal diagnostic tools in specific cases. Techniques with more effectiveness and less adverse effects are expected to improve the treatment outcomes of patients.

\section{REFERENCES}

- Nakamura H, Konishiike J, Sugamura A, Takeno Y, 1986 Mar;89(3):378-82.

- Melton LJ 3rd, Hepper NG, Offord KP, The American Review of Respiratory Disease [1979, 120(6):1379-1382]

- Sadikot, R. T., et al. "Recurrence of primary spontaneous pneumothorax."Thorax 52.9 (1997): 805-809.

- Mathieson, Philip, Ian Reckless, and Colin Ferrett. "Secondary spontaneous pneumothorax: a rare complication of pulmonary embolism." BMJ case reports2012 (2012)

- Melton 3rd, L. J., Hepper, N. G., \& Offord, K. P. (1979). Incidence of spontaneous pneumothorax in Olmsted County, Minnesota: 1950 to 1974 . The American review of respiratory disease, 120(6), 1379.

- $\quad$ Sadikot, R. T., Greene, T., Meadows, K., \& Arnold, A. G. (1997). Recurrence of primary spontaneous pneumothorax. Thorax, 52(9), 805-809.

- Mathieson, P., Reckless, I., \& Ferrett, C. (2012). Secondary spontaneous pneumothorax: a rare complication of pulmonary embolism. BMJ case reports, 2012 .
- $\quad$ Sousa, C., Neves, J., Sa, N., Goncalves, F., Oliveira, J., \& Reis, E. (2011). Spontaneous pneumothorax: a 5-year experience. Journal of clinical medicine research, 3(3), 111.

- Primrose, W. R. (1984). Spontaneous pneumothorax: a retrospective review of aetiology, pathogenesis and management. Scottish medical journal, 29(1), 15.

- Sharma, A., \& Jindal, P. (2008). Principles of diagnosis and management of traumatic pneumothorax. Journal of Emergencies, Trauma and Shock, 1(1), 34.

- $\quad$ Rousset-Jablonski, C., Alifano, M., Plu-Bureau, G., CamilleriBroet, S., Rousset, P., Regnard, J. F., \& Gompel, A. (2011). Catamenial pneumothorax and endometriosis-related pneumothorax: clinical features and risk factors. Human reproduction, 26(9), 2322-2329..

- Guo, Y., Xie, C., Rodriguez, R. M., \& Light, R. W. (2005). Factors related to recurrence of spontaneous pneumothorax. Respirology, 10(3), 378-384.

- Sahn, S. A., \& Heffner, J. E. (2000). Spontaneous pneumothorax. New England Journal of Medicine, 342(12), 868-874.

- Blanco, S., Hernando, F., Gomez, A., Gonzalez, M. J., Torres, A. J., \& Balibrea, J. L. (1998). Catamenial pneumothorax caused by diaphragmatic endometriosis. The Journal of Thoracic and Cardiovascular Surgery, 116(1), 179-180.

- Lillington, G. A., Mitchell, S. P., \& Wood, G. A. (1972). Catamenial pneumothorax.JAMA: The Journal of the American Medical Association, 219(10), 1328-1332.

- Getz Jr, S. B., \& Beasley III, W. E. (1983). Spontaneous pneumothorax. The American Journal of Surgery, 145(6), 823827.

- Alifano, M., Legras, A., Rousset-Jablonski, C., Bobbio, A., Magdeleinat, P., Damotte, D., ... \& Regnard, J. F. (2011). Pneumothorax recurrence after surgery in women: clinicopathologic characteristics and management. The Annals of thoracic surgery, 92(1), 322-326. 